\title{
DIE BETEKENIS VAN DIE MOEDERTAALSKOOL VIR DIE NASIONALE VORMING VAN ONS JEUG.
}

Dit is van besondere betekenis vir die Afrikaner dat in die afgelope twee of drie jaar daar kort-kort 'n Afrikaansmediumskool sy mondigwording gevier het. So het bv. die Hoër Voortrekkerskool op Boksburg twee jaar gelede reeds so'n fees gehad. So het die Hoër Monumentskool op Krugersdorp en die Helpmekaarskool op Johannesburg ook reeds hulle 21jarige bestaan gevier. Van uit die Kaap-Provinsie kom die berig dat daar op Graaff-Reinet die mondigwording gevier word van die eerste skool met Afrikaans as voertaal in Kaapland, nl. die Hoër Volkskool. In 
verband met laasgenoemde fees is daar op 20 Maart by geleentheid van die verjaarsdag van Ds. J. F. Naudé van Graaff-Reinet ook aandag geskenk aan die 25-jarige bestaan van die laerskool op Roodepoort, naby Johannesburg as die eerste skool met Afrikaans as voertaal, omdat Ds. Naudé die stigter hiervan was.

Die betekenisvolle van die gebeurtenisse lê veral daarin dat vir die afgelope 25 jaar die Afrikaner vir die eerste maal in sy hele geskiedenis moedertaalonderwys geniet het deur middel van sy eie skole. Ek bedoel dit: vir die eerste maal is die Afrikaner opgevoed deur middel van die taal wat 'n skeppingsproduk is van die gees van die Boer, die taal wat uit eie bodem ontstaan, gegroei en gebloei het, nl. die Afrikaanse taal. Die geskiedenis het getoon hoedat daar 'n bifurkasie in die taalontwikkeling van die Boer plaasgevind het: die oorspronklike moedertaal het meer en meer onaangepas geword aan die omstandighede waaronder die Boer gewoon het, sodat die meer aangepaste taal (Afrikaans) wat hieruit ontwikkel het, spreektaal geword het, terwyl Hollands veral skryftaal gebly het. In die Afrikaanse skool is spreektaal en skryftaal weer verenig. $V$ andat die Afrikaner 'n nasie geword het met 'n eie moedertaal, het hy geen skool gehad om die eie uitingswyse verder uit te bou nie en was daar omtrent geen eie literatuur, waardeur die gees van die volk gedurig gevoed moet word nic.

Is dit dan 'n wonder dat ons volk vol konflikte en weerspannigheid ds? Lynreg hierteenoor staan die grootste wonder dat ons die verwoestende geestesinvloede getrotseer het soos „die Barre Rots" van die digter Da Costa die woeste golfslae van die see afgeweer het, en Kan ons sê dat ons kulturele fondament vandag hegter as ooit is. Ons moet erken dat daar in die afgelope kwart eeu 'n fenomenale vooruitgang in die proses van nasievorming en kultuurverbreiding plaasgevind het. Hierdie vooruitgang is veral aan tweeërlei feite te danke. Eerstens is dit te danke aan 'n groot hoeveelheid kultuur- en skeppingskrag waarvan die eintlike bron in die kultuurtydperk van 1836-1899 gesoek moet word;

Tweedens is die vooruitgang te danke aan die stigting van moedertaalskole in die twintiger jare van die eeu, wat 'n kanaal geskep het vir die uiting van daardie oormatige latente kultuurkrag. Hierdie skole het ook nuwe stukrag gegee, omdat die moedertaalskool dié middel is wat deur die volk ingeskakel word om onder beskaafde omstandighede aan te sluit by die huisgesin, wat die bakermat is van die taal en kultuur en die skeppingskrag van die volk; dis die middel wat die kultuuroordriging van geslag tot geslag moet bewerkstellig, aangesien in die skool alles beliggaam is wat eie is aan die volk. 
Laat ek daarop wys dat die siel van enige volk smag na sy eie moedertaalskool. Sodra dan ook die omstandighede vir die skool vir die Afrikaner geskep is, was daar 'n onophoudelike stroom van Afrikanerkinders na hierdie eie skool. Om die bewering te bewys wil ek 'n paar syfers noem uit die Bulletin vir Onderwysstatistiek van 1940 wat betrekking het op die bloeitydperk van die Afrikaanse taal en kultuur, d.w.s. die jare 1932 tot 1939 . In 1932 het reeds $49.0 \%$ van die kinders op skool in die Kaap hulle onderwys deur die medium van Afrikaans ontvang, teenoor $33.5 \%$ wat hulle onderwys in Engels ontvang het, terwyl slegs $15.5 \%$ hulle onderwys deur albei voertale ontvang het; in 1939 het $58.2 \%$ kinders in die Kaap hulle onderwys in Afrikaans ontvang, teenoor $32.2 \%$ wat deur Engels hulle onderrig ontvang het, terwyl na sewe jaar daar nou slegs $9.6 \%$ hulle onderwys deur albei media ontvang. Die ooreenkomstige syfers vir Transvaal is in 1932: $57.7 \%$ (Afrikaans), $31.2 \%$ (Engels); $5.1 \%$ (albei media); en in 1939: 64.4\% (Afrikaans), 34.2\% (Engels) en $1.4 \%$ (albei media). Dieselfde Bulletin bevat die volgende samevatting oor die syfers vir die Unie, (bls. 33): „Die persentasie kinders in alle stds. in Suid-Afrika wat hul onderrig in Engelsmediumskole ontvang het, het in sewe jaar stadig afgeneem van $37.4 \%$ to $34.8 \%$. Kinders in Afrikaansmediumskole het in dieselfde tydperk van $52.9 \%$ tot $60.5 \%$ toegeneem. Leerlinge in skole waar albei media, Engels sowel as Afrikaans gebesig word, het ' $n$ vermindering van 9.7 persent tot 4.7 persent getoon-die snelste veranderingspersentasie van die drie neigings hierbo aangedui. Leerlinge in na-primêre Afrikaansmediumskole het met verbasende snelheid vermeerder van 28.2 persent na-primêre leerlinge tot 51.5 persent. Hierdie veranderings word teweeggebring as gevolg van (a) die vermeerderde onderwysfasiliteite op die platteland waar die bevolking meestal Afrikaanssprekend is;

(b) die toenemende besef, veral onder Afrikaanssprekende ouers, van dic belangrikheid van die moederfaal as voertaal." (Ek onderstreep).

Dit is dus duidelik dat die Moedertaalskool van besondere betekenis moet wees vir die bestaan en die voortbestaan van die nasie as 'n geheel. Laat ons dus die betekenis van die moedertaalskool vir die kulturele vorming van ons jeug meer in besonder nagaan en dit afweeg teenoor die invloed van die dubbel- en/of parallelmediumskole. Hierdie betekenis staan in verband met sekere beginsels wat terselfdertyd as maatstaf en rigsnoer kan dien vir enige moedertaalskool.

In die algemeen lê die betekenis van die moedertaalskool daarin dat dit deurtrek moet wees van'n Christelik-Nasionale gees. Hierdie eie Christelik-Nasionale wêreld- en lewensbeskouing moet die grondtoon van 
die skool uitmaak. Ja, teneinde harmonie en eenheid van optrede te verseker moet dit die enigste lewensopvatting in die hele skool wees. Juis om die rede kan die parallel- en/of dubbelmediumskool nie die daadkrag aan die dag lê van die moedertaalskool nie, omdat dit 'n kunsmatig saamgestelde geheel is. Dus ook uit 'n suiwer sosiologiese oogpunt is hierdie andersoortige skool 'n maatskaplike gedrog, waarvan die bestaan lynreg indruis teen die maatskaplike beginsels van groepsvorming. Dit moct mettertyd dus wrange vrugte afwerp.

'n Christelik-Nasionale wêreld- en lewensbeskouing beteken o.a. die oortuiging en die geloof dat God die Almagtige nie net elke mens volgens eie aard en aanleg geskape het nie, maar ook dat hy die Skepper van nasies is; dat dit dus in ooreenstemming met sy wil en sy wêreldplan is dat daar nasies moet wees, elkeen met 'n eie taal en kultuur, en met 'n eie bestemming. So moet elke indiwidu daarvan oortuig wees en glo dat die Afrikanerdom nie 'n menslike maaksel is nie, maar dat dit deur die Wil van God daargestel is en saangesnoer is deur geestelike bande van taal, geskiedenis, godsdiens ens.; en dat elke indiwidu binne hierdie volksgemeenskap tot die hoogste ontplooiing moet en kan kom. Dit behoort vir elkeen duidelik te wees dat hierdie beskouingswyse geensins kan bestaan in 'n mengelmoesskool nie; daarenteë is dit 'n natuurlike geestesopvatting vir sover dit die moedertaalskool betref.

Hierdie Christelik-Nasionale beskouing kan alleen gehandhaaf word wanneer die inhoud van die leerplanne ook Christelik en Nasionaal is. Plek laat dit nie toe om hier uit te wei oor die Christelikheid van die skool en die verhouding wat daar behoort te bestaan tussen Kerk, Staat en Skool nie. Ek wil net daarop wys dat die Protestants-Calvinistiese leer as grondslag moet dien vir die opvoeding en onderwys van die Afrikanerkind. In die woorde van wyle Dr. Fourie moet die Christelike gees in en deur die hele skool heers. "Die Christelike beginsels moet daar geken en bely word en die grondslag vorm van die opvoeding en onderwys."

Onder Nasionale opvoeding word verstaan die geleidelike ontplooing van die gees van die kind in die bedding van sy eie kultuur, m.a.w. die inhoud van die leerplanne moet regstreeks geput word uit die skeppingsprodukte van die nasie, nl. die taal, die kuns, die geskiedenis, die godsdiens ens.

Die betekenis van die skool in die kulturele vormingsproses verstaan 'n mens soveel beter wanneer 'n mens die doel von die skool ontleed. Laat ons die kern hiervan probeer weergee. Elke opvoedingstelsel beoog die vorming van die mens in volste sin van die woord, d.w.s.: 
eerstens, die ontplooiing van die skeppingskrag, van sy estetiese en sedelike vermoëns; tweedens beoog dit die maatskaplike vorming van die mens. Die mens is van nature 'n sosiale wese, en sy skeppingskrag kan dus alleen ontplooi in 'n maatskappy. Derdens, en hierin lê die crux van die kulturele vorming, kan die skeppingsvermoëns nie tot volle ontwikkeling kom in enige soort maatskappy nie. Die mens is alleen mens wanneer hy binne ' $n$ bepaald omskrewe, deur God daargestelde gemeenskap, nl, die nasie ontwikkel.

Die hoogste vorm van kultuurmens word alleen gevind wanneer die indiwidu in en deur die eenheidsgemeenskap, die nasie, ontwikkel, met dien verstande egter dat hy onder dié omstandighede in die regte verhouding tot die Godheid staan, aangesien die mens vanself ook 'n godsdienstige wese is.

In dié lig beskou is dit dus die taak van die skool om die jeugdiges in en deur die kultuur van die nasie op te voed. Uit 'n kulturele oogpunt moet 'n egte nasionale stelsel van opvoeding en onderwys hom veral in drieërlei rigting beywer: (a) die suiwere oordraging van die Afrikaanse taal en kultuur aan die kind; (b) die bestryding van onnasionale elemente wat mag insluip; (c) die verheffing en verfyning en bevordering van die eie taal en kultuur. Ek sal netnou daarop wys dat die parallel- en/of dubbelmediumskool nie hiertoe instaat is nie.

Die vernaamste eis vir 'n skool om te voldoen aan die drie take is dat die moedertaal tot sy volle reg moet kom in daardie skool, en dit kan alleen geskied wanneer die moedertaal die enigste voertaal is.

Die moedertaal is die belangrikste vak in die skool en moet in sy suiwerste vorm aan die kind geleer word. Dis die belangrikste vak in die skool veral om drie redes. Eerstens, dis die hoogste kultuurskepping van enige volk; tweedens, dis die draer van alle kultuur en die middel waardeur alle geestesskeppinge vasgelê en verewig word. Dis dan ook die middel waardeur alle kennis in sy verstaanbaarste vorm aan die kind gebring word; derdens, dis die beste middel vir die geleidelike en spontane ontwikkeling van die gees veral vir die karakter. Die Engelse Staatsverslag oor "The teaching of English" verklaar: "It is self-evident that until a child has acquired a certain command of the native language no educational development is even possible," terwyl Michael West, 'n outoriteit op dié gebied, sê: "All second languages are interchangeable, and are a matter of choice, but the mother tongue is not; it is irreplaceable, unchangeable, is not a language but the foundation stone of personality. A man who forgets his mother tongue forgets himself." 
By wyse van toepassing is dit genocgsaam om op die volgende te wys: Swak moedertaalonderwys, 'n lae gehalte van die moedertaal op ons skole veral in die parallel- en/of dubbelmediumskole, afskeping van die moedertaal, is die oorsaak daarvan dat die meeste Afrikaners ly aan 'n gesplete gedagtegang, vol geesteskonflikte is t.o.v. nasionale vraagstukke, „hink” op twee gedagtes, 'n gebrekkige onderskeidingsvermoë besit tussen die eie en die vreemde, 'n ryk oes anglisismes besit, ja, somtyds so ontaard is dat hulle nóg aan die een, nóg aan die ander volksgroep kan behoort, en dus ooreenstem met die ontaarde groep Belge wat deur die Vlaminge as Franskiljons bestempel word.

Ek het tot dusver genoeg bewyse om te beweer dat die gehalte van die moedertaal in die parallel- en/of dubbelmediumskole laer is as in die enkelmediumskole. Dis nie alleen die moedertaal wat van $\mathrm{n}$ hoë gehalte in die enkelmediumskool is nie, maar ook t.o.v. die tweede taal lewer die suiwer Afrikaansmediumskole beter resultate, m.a.w. is die enkelmediumskool beter in staat tot die suiwerhouding van ons kultuur en dus tot die kulturele vorming van ons jeug. Die eerste bewys is afkomstig van 'n ondersoekie van Transvaalse Inspekteur Robb wat in 1928 die taalprestasies van skole nagegaan het in dubbeltalige en enkeltalige gebiede vir die toelatingseksamen tot die middelbare skool. Die woord „dubbeltalig" gebruik hy i.v.m. 'n stadsgebied wat 'n Engelsmedium sowel as 'n Afrikaansmediumskool bevat. „Enkeltalig" gebruik hy met betrekking tot ' $n$ stadsgebied of buitedistrik waar hoofsaaklik net een taal in gebruik is. Hy het dus die skole as volg geklassifiseer:

A. Engelsmediumskole in 'n enkeltalige gebied.

B. Afrikaansmediumskole in 'n enkteltalige gebied.

C. Engelsmediumskole in ' $n$ dubbeltalige gebied.

D. Afrikaansmediunsskole in ' $n$ dubbeltalige gebied.

Die huistaal word op die hoër graad en die tweede taal op die laer graad geneem.

Sy resultate kom op die volgende neer:-

In die dubbeltalige gebiede waar ouers gewoonlik so spog met die tweetaligheid van hulle kinders, is daar 'n geweldige afname in die persentasie leerlinge wat vir moedertaal in die hoër graad slaag. Dis van groot belang om te weet dat die toestand die Engelse kind swaarder tref. Vir Afrikaanse kinders is die syfers $67.9 \%$ vir enkeltalige gebiede en $58 \%$ vir dubbeltalige gebiede; die syfers vir Engelse kinders is $72 \%$ vir enkeltalige gebiede en slegs $50 \%$ vir dubbeltalige gebiede. In verband met die tweede taal toon die resultate dat in die enkelmediumskole daar elke keer 'n hoër persentasie leerlinge hierin slaag; weer toon die syfers dat die Engelse kind die swaarste ly. 
Hierdie resultate wys baie duidelik dat sodra ons die gehalte van die tweede taal verhef, dan daal die gehalte van die moedertaal, m.a.w. sodra ons by die kind ' $n$ dubbelslagtigheid van denkwyse wil aankweek, dan benadeel ons die peil van die moedertaal en gevolglik ook die kulturele vorming van die kind.

Wanneer ons die kind in die parallel- en/of dubbelmediumskool dwing om die peil van die tweede taal te verhoog dan moet dit noodwendig 'n verlaging van die peil van die moedertaal meebring. Dat dit wel die geval is dat die peil van die moedertaal hoër is in die enkelmediumskole, word bewys in ' $n$ eie ondersoek na die resultate in taalonderwys in die Juniorsertifikaat-eksamen en die matriekeksamen aan die end van 1941. Dit kom daarop neer dat die enkelmediumskole hoër gemiddelde persentasies het vir die moedertaal sowel as vir die tweede taal. Die parallel- en/of dubbelmediumskole staan in elk geval baie laer op die lys.

Dit so ver dit die opvoedkundige standpunt betref. Die voorstanders van parallel- en/of dubbelmediumonderwys bekommer hulle egter nie oor die argumente nie. Hulle is slegs besiel met een slagkreet nl. assimilasie tussen die twee volksgroepe, en die middel wat aangegee word om die proses tot stand te bring, is die parallelmediumskool sover dit die laerskool betref, en dubbelmediumonderwys in die middelbare skole. Die parallelmediumskool sou dan die kinders van die twee volksgroepe op die speelterrein saambring, en gevolglik sou die tweetaligheidsgehalte hierdeur ook verbeter. Hierdie saambring van die kinders en die sogenaamde bevordering van tweetaligheid sou dan die hoofdoel van die skool wees. Tweetaligheid word beklemtoon, ondat, so word beweer, die enkelmediumskool oorsaak daarvan is dat dit by die Afrikaner aan die afneem is.

Sonder om uit te wei oor die vraagstuk van tweetaligheid wil ek dic volgende beweringe maak:

Eerstens: die bewering as sou die tweetaligheid by Afrikaners aan die afneem wees, is nie sonder meer juis nie; inteendeel die Afrikaner het tweetalig gebly vir sover dit van enige Afrikaner verwag word, ja daar is bewyse dat die tweetaligheid selfs verbeter het. Laat ek net daarop wys dat ons geen vergelykinge met, sê, 'n dertig jaar gelede moet maak nie, want toe was daar, so te sê, slegs een taal op die skole, nl. Engels. Die Afrikaner kon toe miskien Engels praat, maar sy eie moedertaal het hy nie geken nie.

Tweedens wil ek daarop wys dat tweetaligheid geen doelstelling van 'n skool is of ook behoort te wees nie. Die tweede taal word aan die kinders geleer slegs uit nuttigheidsoorweginge. 
Derdens wil ek daarop wys dat die beweringe, as sou die parallelmediumskool tweetaligheid bevorder, nie juis is nie. Ek het dit hierbo reeds probeer bewys. Indien die kontakte tussen die verskillende rasgroepe kunsmatig bewerkstellig word, dan bevorder dit wel 'n skyntweetaligheid d.w.s. enersyds 'n geradbraakte Afrikaans vir sover dit die Afrikanerkind betref, en andersyds 'n soort Engels wat deur Engelse self as Anglikaans bestempel word, vir sover dit die Engelse kind betref. Onder dic omstandighede ly die kulturele vorming van die kind.

Let op, ek sê wanneer die kontakte kunsmatig bewerkstellig word, omdat daar genoeg bewyse is dat die twee rasgroepe op die speelterrein altans so te sê nie meng nie. Hiermee is dan ook bewys dat dit onsin is om te beweer: die kinders speel saam, en daarom sal dit die assimilasieproses bevorder.

Eerstens was dit my eie ervaring vyf jaar lank in 'n parallelskool met Afrikaans en Nederlands as voertale dat die Afrikaner-kinders en Nederlandse kinders omtrent nooit met mekaar saamspeel op die speelterrein nie. Trouens daar was genoeg bewyse dat die kinders van die Nederlandse Std. Ill-klas bv. oorhoop lê met die kinders van die Afrikaanse klas.

'n Ondersoekie in die verband deur Mnr. Botes, hoof van die Pretoria-Noordskool, wat op wetenskaplikheid aanspraak kan maak, het dieselfde bewys. Sy resultate kom op die volgende neer: Laat ek eers net daarop wys dat sy ondersock min of meer 80 skole ingesluit het, d.w.s. oor die 5,000 leerlinge uit Afrikaansmedium-skole, oor die 3,000 leerlinge uit Engelsmediumskole, oor die 6,000 leerlinge uit parallelmediumskole. Sy gevolgtrekkeinge is dat $90 \%$ kinders klas vir klas saamspeel, m.a.w. van saamspeel is daar min sprake. Die klein groepies wat nic klas vir klas saam speel nie, doen dit omdat hulle reeds met ander maats gemaak het buite skoolure of om ander redes.

Hoe ons dus ookal mag redeneer, die opvoedkundige standpunt staan vas, nl. dat die moedertaalskool die beste skool is

(a) vir die geestesontwikkeling van ons jeug, d.w.s. vir die intellektuele sosiale, estetiese en sedelike vorming van ons jeug;

(b) vir die kulturele of liewers nasionale vorming van ons kinders.

$\begin{array}{ll}\text { Pretoria. } & \text { B. F. NEL. }\end{array}$ 